\title{
Preparation and thermoelectric properties of $\mathrm{Cu}_{1.8} \mathrm{~S} / \mathrm{CuSbS}_{2}$ composites
}

\author{
Chunmei TANG, Doudou LIANG, Hezhang LI, Kun LUO, Boping ZHANG* \\ Beijing Municipal Key Laboratory of New Energy Materials and Technologies, School of Materials \\ Science and Engineering, University of Science and Technology Beijing, Beijing 100083, China
}

Received: July 6, 2018; Revised: September 27, 2018; Accepted: November 21, 2018

(C) The Author(s) 2019.

\begin{abstract}
Chalcostibite $\left(\mathrm{CuSbS}_{2}\right)$ is composed of earth-abundant elements and has a proper band gap $\left(E_{\mathrm{g}}=1.05 \mathrm{eV}\right)$ as a thermoelectric (TE) material. Herein, we report the TE properties in the $\mathrm{CuSbS}_{2}$ based composites with a mole ratio of $(1-x) \mathrm{CuSbS}_{2}-x \mathrm{Cu}_{1.8} \mathrm{~S}(x=0,0.1,0.2,0.3)$, which were prepared by mechanical alloying (MA) combined with spark plasma sintering (SPS). X-ray diffraction (XRD) and back-scattered electron image (BSE) results indicate that a single phase of $\mathrm{CuSbS}_{2}$ is synthesized at $x=0$ and the samples consist of $\mathrm{CuSbS}_{2}, \mathrm{Cu}_{3} \mathrm{SbS}_{4}$, and $\mathrm{Cu}_{12} \mathrm{Sb}_{4} \mathrm{~S}_{13}$ at $0.1 \leqslant x \leqslant 0.3$. The correlation between the phase structure, microstructure, and TE transport properties of the bulk samples is established. The electrical conductivity increases from 0.14 to $50.66 \mathrm{~S} \cdot \mathrm{cm}^{-1}$ at $723 \mathrm{~K}$ and at $0 \leqslant x \leqslant 0.03$, while the Seebeck coefficient holds an appropriate value of $190.51 \mu \mathrm{V} \cdot \mathrm{K}^{-1}$. The highest $Z T$ value of 0.17 is obtained at $723 \mathrm{~K}$ and at $x=0.3$ owing to the combination of a high $P F$ $183 \mu \mathrm{W} \cdot \mathrm{m}^{-1} \cdot \mathrm{K}^{-2}$ and a low $\kappa 0.8 \mathrm{~W} \cdot \mathrm{m}^{-1} \cdot \mathrm{K}^{-1}$.
\end{abstract}

Keywords: $\mathrm{CuSbS}_{2}$; phase structure; $Z T$; thermoelectric

\section{Introduction}

Thermoelectric (TE) materials have caused extensive attention due to their potential applications in converting waste heat into electrical power and solid state refrigeration [1]. The conversion efficiency of TE materials is generally evaluated by the dimensionless figure of merit $Z T=\alpha^{2} \sigma T / \kappa$, where $\alpha$ is the Seebeck coefficient, $\sigma$ is the electrical conductivity, $T$ is the absolute temperature, and $\kappa$ is the total thermal conductivity (the sum of the electronic thermal conductivity $\left(\kappa_{\mathrm{e}}\right)$ and the lattice thermal conductivity $\left.\left(\kappa_{\mathrm{L}}\right)\right) . \kappa_{\mathrm{L}}$ can be considered as an independent TE

* Corresponding author.

E-mail: sendaimr@foxmail.com parameter, while $\alpha, \sigma$, and $\kappa_{\mathrm{e}}$ are interconnected closely by the carrier concentration $(n)$. The outstanding performance of TE materials requires a large $\alpha$, a high $\sigma$, as well as a low $\kappa$. Today, $\mathrm{Bi}_{2} \mathrm{Te}_{3}$-based and PbTe-based TE materials have been applied in cooling devices and power generation. However, expensive (Te) and toxic $(\mathrm{Pb})$ elements limit their market applications.

Chalcostibite $\left(\mathrm{CuSbS}_{2}\right)$ belongs to the compounds with the formula of $\mathrm{ABX}_{2}$, where $\mathrm{A}$ is $\mathrm{Cu}, \mathrm{Ag}$, or $\mathrm{Au}, \mathrm{B}$ is $\mathrm{As}, \mathrm{Sb}$, or $\mathrm{Bi}$, and $\mathrm{X}$ is $\mathrm{S}, \mathrm{Se}$, or Te. $\mathrm{CuSbS}_{2}$ is more earth-abundant, less toxic, and cheaper compared with the compounds which include $\mathrm{Ag}, \mathrm{Au}, \mathrm{Se}$, and $\mathrm{Te}$ elements [2]. In the orthorhombic crystal structure of $\mathrm{CuSbS}_{2}$, the $\mathrm{Cu}$ and $\mathrm{Sb}$ atoms occupy the cation sites and they are coordinated by four and three $\mathrm{S}$ atoms, respectively [3]. $\mathrm{CuSbS}_{2}, \mathrm{Cu}_{3} \mathrm{SbS}_{3}$ (skinnerite), $\mathrm{Cu}_{3} \mathrm{SbS}_{4}$ 
(famatinnite), and $\mathrm{Cu}_{12} \mathrm{Sb}_{4} \mathrm{~S}_{13}$ (tetrahedrite) are the four main crystalline phases in the $\mathrm{Cu}-\mathrm{Sb}-\mathrm{S}$ system. Three temperature-dependent crystal structures of $\mathrm{Cu}_{3} \mathrm{SbS}_{3}$ are orthorhombic with space group $P 2_{1} 2_{1} 2_{1}$ below $263 \mathrm{~K}$, monoclinic with space group $P 2_{1} / c$ between 263 and $395 \mathrm{~K}$, and orthorhombic with space group Pnma above $395 \mathrm{~K}$, respectively [4]. The low phase transition temperature for $\mathrm{Cu}_{3} \mathrm{SbS}_{3}$ may lead to micro-cracking during thermal cycling process, which is a potential problem for applications. $\mathrm{Cu}_{3} \mathrm{SbS}_{4}$ has a tetragonal structure with the space group $I \overline{4} 2 \mathrm{~m}$ and lattice parameters of $a=b=5.3850 \AA$ and $c=10.7540 \AA$, whose electrical resistance $(\rho)$ and $\kappa$ are as high as ca. $250 \mathrm{~m} \Omega \cdot \mathrm{cm}$ and $1.8 \mathrm{~W} \cdot \mathrm{m}^{-1} \cdot \mathrm{K}^{-1}$, which means a low TE performance [5,6]. $\mathrm{Cu}_{12} \mathrm{Sb}_{4} \mathrm{~S}_{13}$ has a cubic structure with the space group $I \overline{4} 3 \mathrm{~m}$ and lattice parameters of $a=b=c=10.3293 \AA$. Many researches have shown that $Z T$ value of intrinsic $\mathrm{Cu}_{12} \mathrm{Sb}_{4} \mathrm{~S}_{13}$ lies in 0.3 0.5 [7-9]. Among the $\mathrm{Cu}-\mathrm{Sb}-\mathrm{S}$ system, Kumar et al. [10] report via a theoretic calculation that $\mathrm{CuSbS}_{2}$ has a proper band gap $\left(E_{\mathrm{g}}=1.05 \mathrm{eV}\right)$ and a large $\alpha$, indicating $\mathrm{CuSbS}_{2}$ may be a promising TE material, whose TE performance has rarely been reported until now. The $\sigma$ of $\mathrm{CuSbS}_{2}$ films was reported to be 0.03 [11], $10^{-4}-10^{-3}$ [12], and $10^{-5} \mathrm{~S} \cdot \mathrm{cm}^{-1}$ [13], indicating the importance via obtaining a higher $\sigma$ to enhance the TE performance of $\mathrm{CuSbS}_{2}$. Copper sulfides $\left(\mathrm{Cu}_{2-x} \mathrm{~S}, 0 \leqslant\right.$ $x \leqslant 1$ ) have recently attracted extensive attention as TE materials benefiting from the inexpensive, nontoxic, and earth-abundant elements of $\mathrm{Cu}$ and $\mathrm{S}[2,14]$. Among $\mathrm{Cu}_{2-x} \mathrm{~S}$ compounds, $\mathrm{Cu}_{1.8} \mathrm{~S}$ is considered to be a promising TE material due to the stable structure and the feature of the superionic conductor. Owing to the high mobility of $\mathrm{Cu}$ ions in the lattice, the $\sigma$ of $\mathrm{Cu}_{1.8} \mathrm{~S}$ was reported to be $3500 \mathrm{~S} \cdot \mathrm{cm}^{-1}$ at $373 \mathrm{~K}$ [15] and $2815 \mathrm{~S} \cdot \mathrm{cm}^{-1}$ at $323 \mathrm{~K}[16]$.

In the present work, the high-conductive $\mathrm{Cu}_{1.8} \mathrm{~S}$ was composited with $\mathrm{CuSbS}_{2}$ in the mole ratio of $(1-x) \mathrm{CuSbS}_{2}-x \mathrm{Cu}_{1.8} \mathrm{~S}(x=0,0.1,0.2,0.3)$ to enhance the electrical transport properties of $\mathrm{CuSbS}_{2}$. The correlation between the phase structure, microstructure, and TE transport properties of the bulk samples was established.

\section{Experimental}

\section{1 Preparation}

$\mathrm{CuSbS}_{2}$ powders were prepared by mechanical alloying
(MA) using a planetary ball mill (QM-1SP2, Nanjing University, China). The mixed $\mathrm{Cu}(99.7 \%)$, $\mathrm{Sb}$ (99.999\%), and S (99.5\%) raw powders were milled firstly at $425 \mathrm{rpm}$ for $10 \mathrm{~h}$ in a mixed atmosphere of high-purity $\mathrm{Ar}(95 \%)$ and $\mathrm{H}_{2}(5 \%)$ gases and then at $300 \mathrm{rpm}$ for $2 \mathrm{~h}$ after adding $50 \mathrm{~mL}$ alcohol to the stainless steel vessel. The weight ratio of the stainless steel ball to powder was kept at 20:1. $\mathrm{Cu}_{1.8} \mathrm{~S}$ was prepared by MA method described by Ref. [15]. $\mathrm{Cu}_{1.8} \mathrm{~S}$ powder was mixed with $\mathrm{CuSbS}_{2}$ powder in a mole ratio of $(1-x) \mathrm{CuSbS}_{2}-x \mathrm{Cu}_{1.8} \mathrm{~S}$ at $200 \mathrm{rpm}$ for $0.5 \mathrm{~h}$, where $x$ was fixed at $0,0.1,0.2$, and 0.3 . The corresponding powders were sintered at $723 \mathrm{~K}$ for $5 \mathrm{~min}$ in a $\Phi=20 \mathrm{~mm}$ graphite mould under an axial pressure of $50 \mathrm{MPa}$ in a vacuum using SPS system (Sumitomo SPS1050, Japan) to obtain the bulk samples [17].

\section{2 Characterization methods}

The phase structure was identified by X-ray diffraction (XRD, Rigaku Dmax-RB, Japan) with a $\mathrm{Cu} \mathrm{K} \alpha$ radiation filtered through a Ni foil. The phase purity was refined by the Rietveld method using the Materials Studio (MS) software over the $2 \theta$ angular range of $20^{\circ}-60^{\circ}$. The microstructure and grain morphology of the bulk samples were observed by field emission scanning electron microscopy (FESEM, SUPRATM 55, Japan). The $\alpha$ and $\sigma$ were simultaneously measured from 373 to $723 \mathrm{~K}$ in a helium atmosphere using a Seebeck coefficient/electrical resistance measurement system (ZEM-2, Ulvac-Riko, Japan). The $\kappa$ was calculated by the formula of $\kappa=D C_{p} d$, where the thermal diffusivity $(D)$ was measured by the laser flash method (NETZSCH, LFA457, Germany), the specific heat capacity $\left(C_{p}\right)$ was measured via the thermal analysis device (NETZSCH DSC 404C, Germany), and the density (d) was measured by the Archimedes method.

\section{Results and discussion}

\section{1 Phase structure}

Figure 1(a) shows the XRD patterns of bulk samples with the mole ratio of $(1-x) \mathrm{CuSbS}_{2}-x \mathrm{Cu}_{1.8} \mathrm{~S}(x=0$, $0.1,0.2,0.3)$. All the diffraction peaks at $x=0$ are consistent with the pattern of the orthorhombic $\mathrm{CuSbS}_{2}$ (O, PDF\#88-0822), whose space group and unit cell dimension are Pnma (No. 62) and $6.0160 \AA \times 3.7968 \AA \times$ $14.4990 \AA<90^{\circ} \times 90^{\circ} \times 90^{\circ}>$, respectively, indicating 
a formation of a single phase without any impurity phase within the detectable limit of the XRD spectrometer. To further confirm whether the pure $\mathrm{CuSbS}_{2}$ phase was prepared, corresponding X-ray Rietveld refinement profiles achieved at $x=0$ are shown in Fig. 1(b). The experimental pattern (observed) is well fitted with the theoretically simulated one (calculated). A high accuracy in the fitting is observed, where the differences provided at the middle of the patterns are almost linear except at the peak position, and the fitting accuracy converging to the acceptable Rietveld parameter $R w p$ is $12.97 \%$. The lattice parameter values are $6.0231 \AA \times 3.8033 \AA \times 14.5036 \AA$, which are similar to $6.0160 \AA \times 3.7968 \AA \times 14.4990 \AA$ of the standard card $\left(\mathrm{CuSbS}_{2}, \mathrm{PDF} \# 88-0822\right)$. It is reasonable that a pure $\mathrm{CuSbS}_{2}$ phase was synthesized by MA combining with SPS. As shown in Fig. 1(c), the diffraction peaks for $\mathrm{Cu}_{1.8} \mathrm{~S}$ powder and bulk correspond well to the rhombohedral $\mathrm{Cu}_{1.8} \mathrm{~S}$ (PDF\#47-1748) without any second phases within the detectable limit of XRD. The corresponding X-ray Rietveld refinement profiles for $\mathrm{Cu}_{1.8} \mathrm{~S}$ powder were also achieved.

When $0.1 \leqslant x \leqslant 0.3$, no $\mathrm{Cu}_{1.8} \mathrm{~S}$ phase was detected, while some second phases identified to tetragonal $\mathrm{Cu}_{3} \mathrm{SbS}_{4}(\diamond, \mathrm{PDF} \# 71-0555)$ and cubic $\mathrm{Cu}_{12} \mathrm{Sb}_{4} \mathrm{~S}_{13}$ ( $\star$, PDF\#88-0282) were observed. The calculated formation energy from density functional theory (DFT) is in order of $-0.200,-0.359,-0.377$, and $-0.394 \mathrm{eV} /$ atom for $\mathrm{Cu}_{1.8} \mathrm{~S}, \mathrm{Cu}_{12} \mathrm{Sb}_{4} \mathrm{~S}_{13}, \mathrm{Cu}_{3} \mathrm{SbS}_{4}$, and $\mathrm{CuSbS}_{2}[18,19]$, respectively, which is also the sorting of structural instability, where $\mathrm{Cu}_{1.8} \mathrm{~S}$ is the most unstable compared with $\mathrm{Cu}_{12} \mathrm{Sb}_{4} \mathrm{~S}_{13}, \mathrm{Cu}_{3} \mathrm{SbS}_{4}$, and $\mathrm{CuSbS}_{2}$. In order to discuss the effect of $x$ on the phase structure, some diffraction peaks of $\mathrm{CuSbS}_{2}, \mathrm{Cu}_{3} \mathrm{SbS}_{4}$ and $\mathrm{Cu}_{12} \mathrm{Sb}_{4} \mathrm{~S}_{13}$ with the highest and/or higher intensities are highlighted in Figs. 2(a)-2(d), whose $2 \theta$ angle and diffraction intensity are abbreviated as $2 \theta_{\text {phase }}^{(h k l)}$ and $I_{\text {phase }}^{(h k l)}$, respectively. The absent peaks at $2 \theta_{\mathrm{Cu}_{3} \mathrm{SbS}_{4}}^{(200)}$ (Fig. 2(b)) and $2 \theta_{\mathrm{Cu}_{12} \mathrm{Sb}_{4} \mathrm{~S}_{13}}^{(5)_{13}}$ (Fig. 2(d)) also confirm the formation of the pure $\mathrm{CuSbS}_{2}$ phase at $x=0$. Due to the increased $\mathrm{Cu}_{3} \mathrm{SbS}_{4}$ and $\mathrm{Cu}_{12} \mathrm{Sb}_{4} \mathrm{~S}_{13}$, obviously increased $I_{\mathrm{CuSbS}_{2}}^{(104)}$ and $I_{\mathrm{CuSbS}_{2}}^{(013)}$ were observed because of the peak overlap between $2 \theta_{\mathrm{Cu}_{3} \mathrm{SbS}_{4}}^{(12)}$ and $2 \theta_{\mathrm{CuSbS}_{2}}^{(104)}$, $2 \theta_{\mathrm{Cu}_{12} \mathrm{Sb}_{4} \mathrm{~S}_{13}}^{(222)}$ and $2 \theta_{\mathrm{CuSbS}_{2}}^{(013)}$. Along with the variation of the phase structure, the diffraction peaks show a peak shifting apart from the varied $I_{\text {phase }}^{(h k l)} \cdot 2 \theta_{\mathrm{CuSbS}_{2}}^{(111)}$ and $2 \theta_{\mathrm{CuSbS}_{2}}^{(200)}$ at $x=0$ in Figs. 2(a) and 2(c) are ca. $28.420^{\circ}$ and $29.640^{\circ}$ which are lower than those $\left(28.448^{\circ}\right.$ and $\left.29.675^{\circ}\right)$ of the standard card $\left(\mathrm{CuSbS}_{2}, \mathrm{PDF} \# 88-0822\right)$ indicating an expanded $\mathrm{CuSbS}_{2}$ lattice. A similar behavior was usually found in sulfur containing systems, which is attributed to the volatilization and/or loss of $\mathrm{S}$ in the MA and/or SPS process [14-16,20]. The shifting trend of $2 \theta_{\mathrm{CuSbS}_{2}}^{(111)}$ and $2 \theta_{\mathrm{CuSbS}_{2}}^{(200)}$ to high angle is observed at $x=0.1$, but turns to weaken by further increasing $x$ to 0.2 and even reversely shifts to low angle at $x=0.3$, which reflects the shrinkage and enlargement of $\mathrm{CuSbS}_{2}$ lattice.
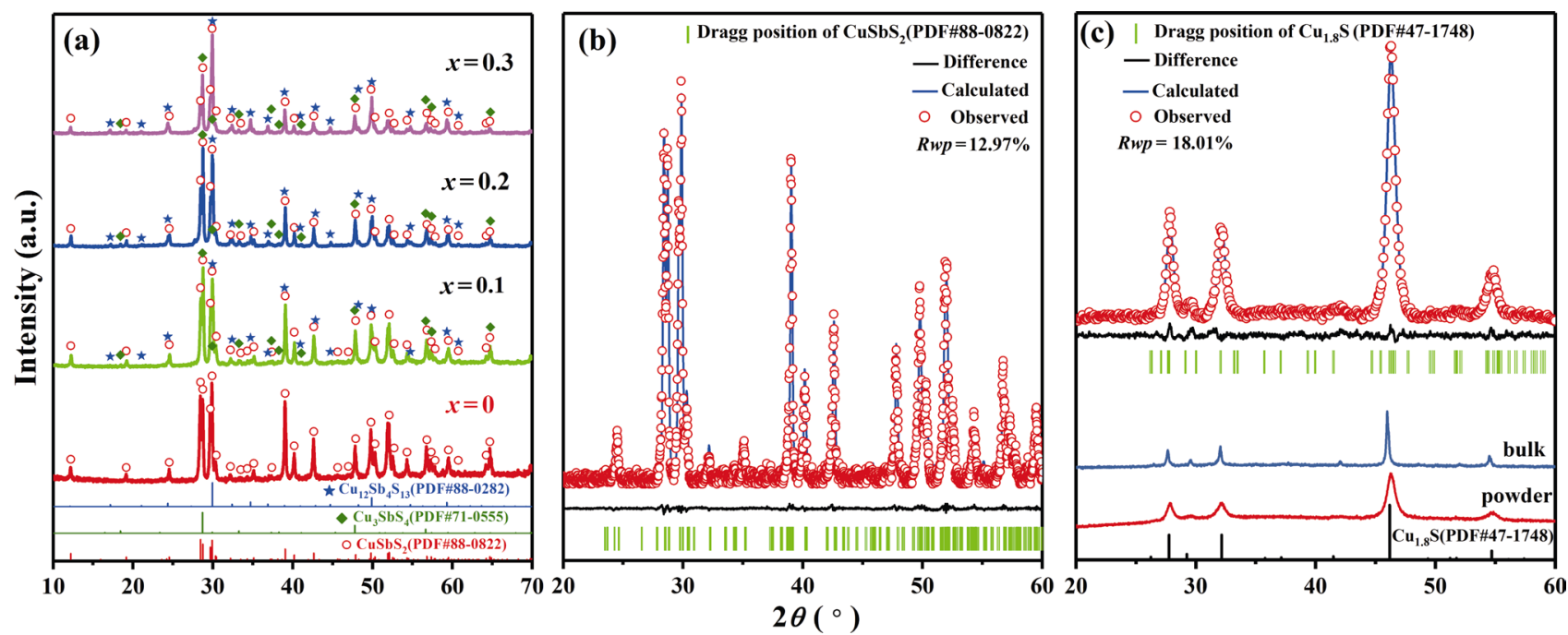

Fig. 1 (a) XRD patterns of the bulk samples with the mole ratio of $(1-x) \mathrm{CuSbS}_{2}-x \mathrm{Cu}_{1.8} \mathrm{~S}(x=0,0.1,0.2,0.3)$, (b) Rietveld refinement of $x=0$ bulk sample, and (c) XRD patterns and Rietveld refinement of $\mathrm{Cu}_{1.8} \mathrm{~S}$. 


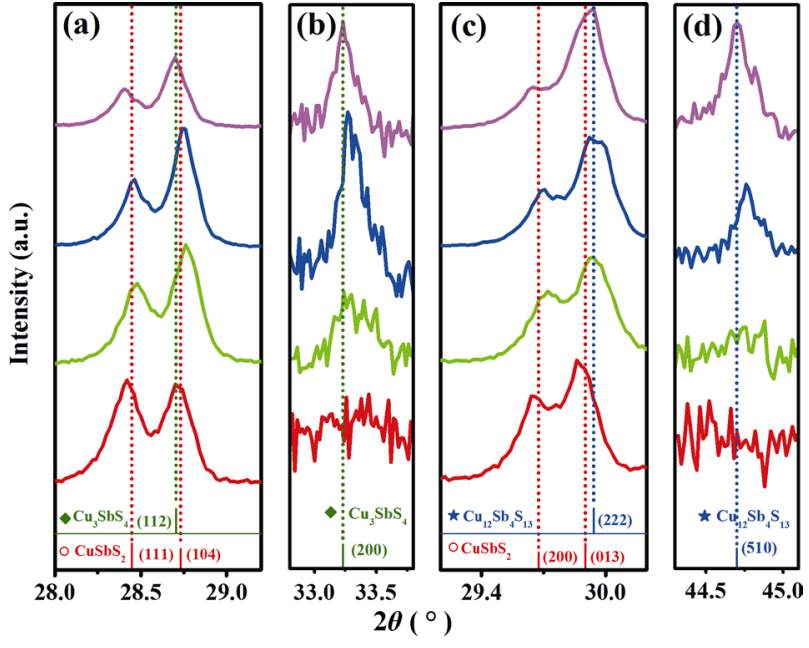

Fig. 2 XRD patterns of the bulk samples with the mole ratio of $(1-x) \mathrm{CuSbS}_{2}-x \mathrm{Cu}_{1.8} \mathrm{~S}(x=0,0.1,0.2,0.3)$ at $2 \theta$ range of (a) $28^{\circ}-29^{\circ}$, (b) $32.8^{\circ}-33.8^{\circ}$, (c) $29.2^{\circ}-30.2^{\circ}$, and (d) $44.3^{\circ}-45.1^{\circ}$.

Because the $\mathrm{Cu} / \mathrm{S}$ ratio of the $\mathrm{Cu}_{1.8} \mathrm{~S}(\mathrm{Cu} / \mathrm{S}=1.8: 1)$ is far higher than that of $\mathrm{CuSbS}_{2}(\mathrm{Cu} / \mathrm{S}=1: 2)$, the $\mathrm{Cu}$-rich environment may be created by the addition of $\mathrm{Cu}_{1.8} \mathrm{~S}$, which may lead to the formation of $\mathrm{Cu}_{3} \mathrm{SbS}_{4}$, $\mathrm{Cu}_{12} \mathrm{Sb}_{4} \mathrm{~S}_{13}$, and $\mathrm{Cu}_{1+y} \mathrm{SbS}_{2}$ (Cu-rich $\mathrm{CuSbS}_{2}$ phase), where $y$ increases with the increase of $x$ and shows a doping effect. The effect of substitution solution on the lattice parameters is related to the ionic radius of dopants, while the interstitial solution would generally enlarge the lattice parameters. Because the ionic radius (r) of $\mathrm{Cu}^{+}, \mathrm{Cu}^{2+}$, and $\mathrm{Sb}^{3+}$ is $0.60,0.57$, and $0.76 \AA$, respectively, the shrinkage of $\mathrm{CuSbS}_{2}$ lattice is attributed to the substitution of $\mathrm{Sb}^{3+}(r=0.76 \AA)$ by $\mathrm{Cu}^{+}(r=0.60 \AA)$ and/or $\mathrm{Cu}^{2+}(r=0.57 \AA)$ and the enlargement of $\mathrm{CuSbS}_{2}$ lattice is attributed to the interstice solution of rich $\mathrm{Cu}^{+}$and/or $\mathrm{Cu}^{2+}$. When $x$ increases from 0.2 to 0.3 , the interstice solution would weaken the effect of substitution solution on the lattice parameters and even play a dominant role. $I_{\mathrm{Cu}_{3} \mathrm{SbS}_{4}}^{(200)}$ increases when $0 \leqslant x \leqslant 0.2$ and then decreases at $x=0.3$ in Fig. 2(b), while $I_{\mathrm{Cu}_{12} \mathrm{Sb}_{4} \mathrm{~S}_{13}}^{(510)}$ shows a continuous enhancement when $0 \leqslant x \leqslant 0.3$ in Fig. 2(d). Hence, Eqs. (1)-(6) related to the above behaviors should be as follows:

$$
\begin{gathered}
\mathrm{CuSbS}_{2} \rightarrow \mathrm{CuSbS}_{2-z}+z \mathrm{~S} \uparrow \text { or loss }+z V_{\mathrm{S}}^{\bullet \bullet}+2 z \mathrm{e}^{\prime} \\
x \ll \mathrm{u}_{1.8} \mathrm{~S} \stackrel{\mathrm{CuSbS}_{2}}{\longrightarrow} \mathrm{Cu}_{1+y} \mathrm{SbS}_{2} \\
+\beta \mathrm{Cu}_{12} \mathrm{Sb}_{4} \mathrm{~S}_{13}+\mathrm{Cu}_{3} \mathrm{SbS}_{4}
\end{gathered}
$$

$$
\begin{gathered}
y_{1} \mathrm{Cu} \stackrel{\mathrm{CuSbS}_{2}}{\longrightarrow} y_{1} \mathrm{Cu}_{\mathrm{Sb}}^{\prime}+\mathrm{Cu}_{\mathrm{Cu}} \\
+\left(1-y_{1}\right) \mathrm{Sb}_{\mathrm{Sb}}+2 \mathrm{~S}_{\mathrm{S}}+y_{1} h^{\bullet} \\
y_{2} \mathrm{Cu} \stackrel{\mathrm{CuSbS}_{2}}{\longrightarrow} y_{2} \mathrm{Cu}_{\mathrm{Sb}}^{\prime \prime}+\mathrm{Cu}_{\mathrm{Cu}} \\
+\left(1-y_{2}\right) \mathrm{Sb}_{\mathrm{Sb}}+2 \mathrm{~S}_{\mathrm{S}}+2 y_{2} h^{\bullet} \\
y_{3} \mathrm{Cu} \stackrel{\mathrm{CuSbS}_{2}}{\longrightarrow} y_{3} \mathrm{Cu}_{\mathrm{i}}^{\bullet}+\mathrm{Cu}_{\mathrm{Cu}}+\mathrm{Sb}_{\mathrm{Sb}}+2 \mathrm{~S}_{\mathrm{S}}+y_{3} \mathrm{e}^{\prime} \\
y_{4} \mathrm{Cu} \stackrel{\mathrm{CuSbS}_{2}}{\longrightarrow} y_{4} \mathrm{Cu}_{\mathrm{i}}^{\bullet \bullet}+\mathrm{Cu}_{\mathrm{Cu}}+\mathrm{Sb}_{\mathrm{Sb}}+2 \mathrm{~S}_{\mathrm{S}}+2 y_{4} \mathrm{e}^{\prime}
\end{gathered}
$$

where, $z$ is the content of volatilization and/or loss $\mathrm{S}$ during the MA and/or SPS process which depends on the preparation condition, $y$ is the content of $\mathrm{Cu}$ rich in $\mathrm{Cu}_{1+y} \mathrm{SbS}_{2}$ and the sum of $y_{1}$ to $y_{4}$. Equation (1) indicates that the vacancy $V_{\mathrm{S}}^{\bullet \bullet}$ and two electrons $\left(\mathrm{e}^{\prime}\right)$ would generate when $\mathrm{S}$ is lacking $[14,16,20]$. Equation (2) indicates the formation of $\mathrm{Cu}_{1+y} \mathrm{SbS}_{2}, \mathrm{Cu}_{3} \mathrm{SbS}_{4}$, and $\mathrm{Cu}_{12} \mathrm{Sb}_{4} \mathrm{~S}_{13}$. The substitution of $\mathrm{Sb}^{3+}$ by $\mathrm{Cu}^{+}$and/or $\mathrm{Cu}^{2+}$ in Eqs. (3) and (4) would introduce one and/or two holes $\left(h^{\bullet}\right)$ and shrink the $\mathrm{CuSbS}_{2}$ lattice, while the interstice solution of $\mathrm{Cu}^{+}$and/or $\mathrm{Cu}^{2+}$ in Eqs. (5) and (6) would introduce one and/or two $\mathrm{e}^{\prime}$ and enlarge the $\mathrm{CuSbS}_{2}$ lattice.

The actual mole ratio of $\mathrm{CuSbS}_{2}, \mathrm{Cu}_{3} \mathrm{SbS}_{4}$, and $\mathrm{Cu}_{12} \mathrm{Sb}_{4} \mathrm{~S}_{13}$ was calculated by Eqs. (7) and (8) [21] according to the XRD peak differentiating analysis in Fig. 3, where $A_{\text {phase }}^{(h k l)}$ is the peak area and the results are listed in Table 1. The volume ratio of $\mathrm{CuSbS}_{2}$ : $\mathrm{Cu}_{3} \mathrm{SbS}_{4}: \mathrm{Cu}_{12} \mathrm{Sb}_{4} \mathrm{~S}_{13}$ changes from 0.7919:0.0407: 0.1674 at $x=0.1$ to $0.2968: 0.0854: 0.6178$ at $x=0.3$ when $x$ increases. The significantly increased second phases would greatly impact on the TE performance of the matrix which would be discussed in detail later.

$$
\begin{gathered}
\frac{\mathrm{Cu}_{3} \mathrm{SbS}_{4}}{\mathrm{CuSbS}_{2}}=\frac{A_{\mathrm{Cu}_{3} \mathrm{SbS}_{4}}^{(112)}+A_{\mathrm{Cu}_{3} \mathrm{SbS}_{4}}^{(220)}+A_{\mathrm{Cu}_{3} \mathrm{SbS}_{4}}^{(312)}}{A_{\mathrm{CuSbS}_{2}}^{(111)}+A_{\mathrm{CuSbS}_{2}}^{(104)}+A_{\mathrm{CuSbS}_{2}}^{(011)}} \\
\frac{\mathrm{Cu}_{12} \mathrm{Sb}_{4} \mathrm{~S}_{13}}{\mathrm{CuSbS}_{2}}=\frac{A_{\mathrm{Cu}_{12} \mathrm{Sb}_{4} \mathrm{~S}_{13}}^{(222)}+A_{\mathrm{Cu}_{12} \mathrm{Sb}_{4} \mathrm{~S}_{13}}^{(400)}+A_{\mathrm{Cu}_{12} \mathrm{Sb}_{4} \mathrm{~S}_{13}}^{(440)}}{A_{\mathrm{CuSbS}_{2}}^{(111)}+A_{\mathrm{CuSbS}_{2}}^{(104)}+A_{\mathrm{CuSbS}_{2}}^{(013)}}
\end{gathered}
$$

\section{2 Microstructure}

Figures 4(a) and 4(b) show the back-scattered electron (BSE) images of bulk samples with the mole ratio of $(1-x) \mathrm{CuSbS}_{2}-x \mathrm{Cu}_{1.8} \mathrm{~S}(x=0.2,0.3)$. The second phases distribute evenly in the matrix along with an increased content when $x$ increases from 0.2 to 0.3 , which corresponds well to the XRD results (Figs. 1(a), 2(b), and 2(d)). Figures 4(c)-4(g) show the enlarged BSE 

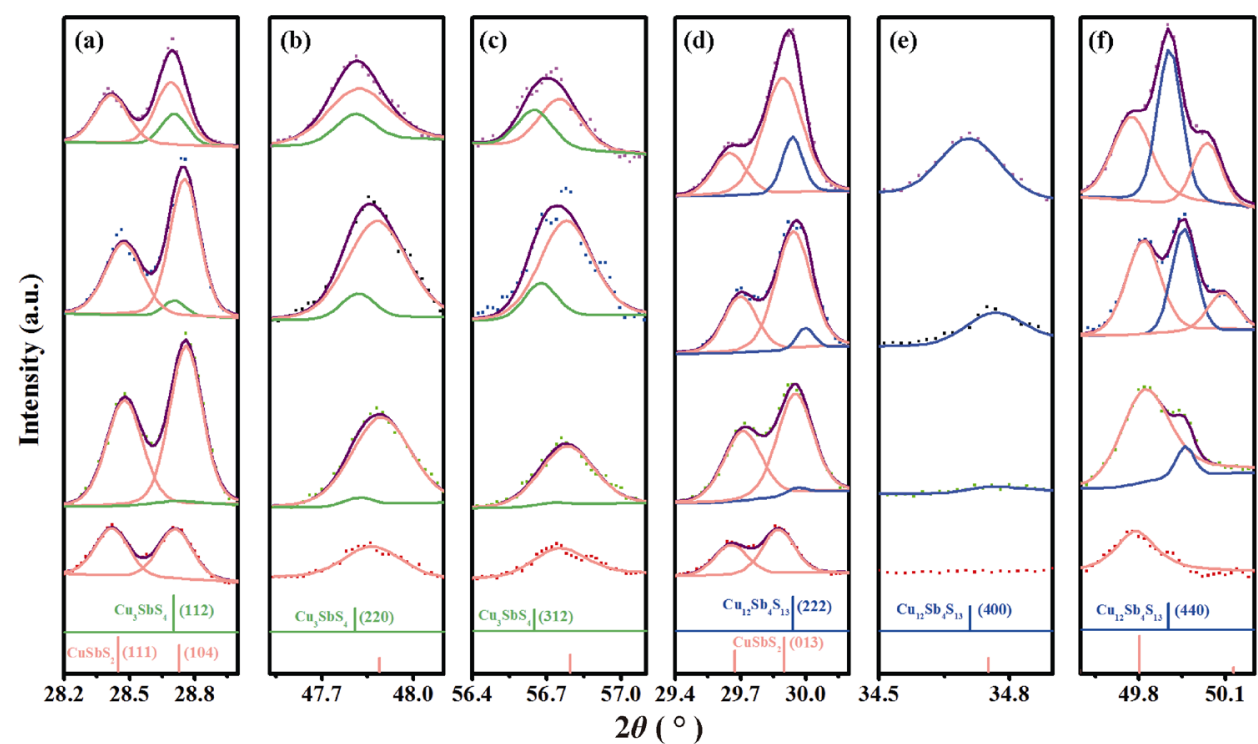

Fig. 3 XRD patterns of the bulk samples with the mole ratio of $(1-x) \mathrm{CuSbS}_{2}-x \mathrm{Cu}_{1.8} \mathrm{~S}(x=0,0.1,0.2,0.3)$ at $2 \theta$ range of (a) $28.2^{\circ}-29.0^{\circ}$, (b) $47.5^{\circ}-48.1^{\circ}$, (c) $56.4^{\circ}-57.1^{\circ}$, (d) $29.4^{\circ}-30.2^{\circ}$, (e) $34.5^{\circ}-34.9^{\circ}$, and (f) $49.6^{\circ}-50.2^{\circ}$.

Table 1 Actual ratio of $\mathrm{CuSbS}_{2}: \mathrm{Cu}_{3} \mathrm{SbS}_{4}: \mathrm{Cu}_{12} \mathrm{Sb}_{4} \mathrm{~S}_{13}$ for the bulk samples with the mole ratio of (1-x)CuSbS$-x \mathrm{Cu}_{1.8} \mathrm{~S}$ at room temperature

\begin{tabular}{|c|c|c|c|c|c|}
\hline \multirow{2}{*}{ Sample } & \multicolumn{2}{|c|}{$\mathrm{CuSbS}_{2}: \mathrm{Cu}_{3} \mathrm{SbS}_{4}: \mathrm{Cu}_{12} \mathrm{Sb}_{4} \mathrm{~S}_{13}$} & \multirow{2}{*}{ Theory density $\left(\mathrm{g} / \mathrm{cm}^{3}\right)$} & \multirow{2}{*}{ Test density $\left(\mathrm{g} / \mathrm{cm}^{3}\right)$} & \multirow{2}{*}{ Relative density (\%) } \\
\hline & Mole ratio & Volume ratio & & & \\
\hline$x=0$ & 1:0:0 & $1: 0: 0$ & 5.0010 & 4.1270 & 82.52 \\
\hline$x=0.1$ & 1:0.0273:0.0324 & 0.7919:0.0407:0.1674 & 4.9917 & 4.1740 & 83.62 \\
\hline$x=0.2$ & 1:0.0620:0.0969 & $0.5717: 0.0668: 0.3615$ & 4.9876 & 4.4140 & 88.59 \\
\hline$x=0.3$ & 1:0.1528:0.3189 & 0.2968:0.0854:0.6178 & 4.9870 & 4.2125 & 84.47 \\
\hline
\end{tabular}

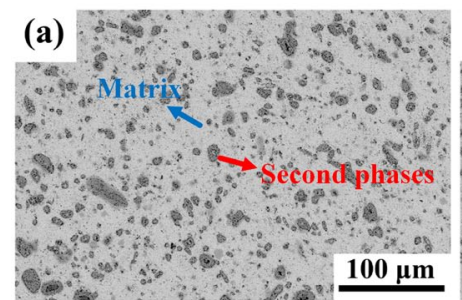

(d)
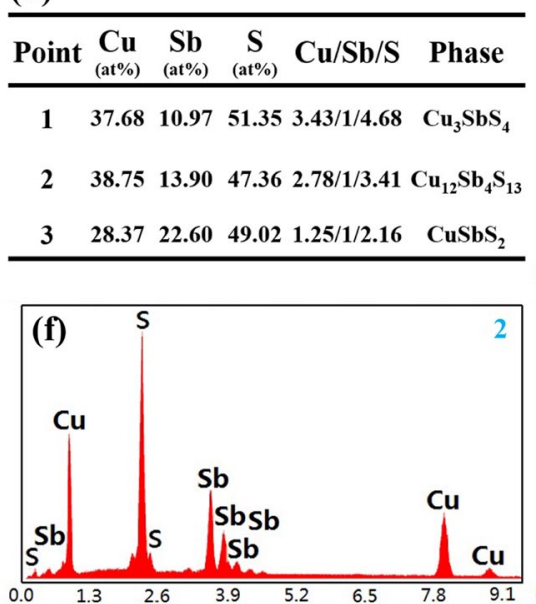

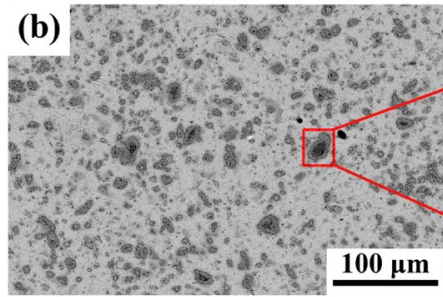

(c)
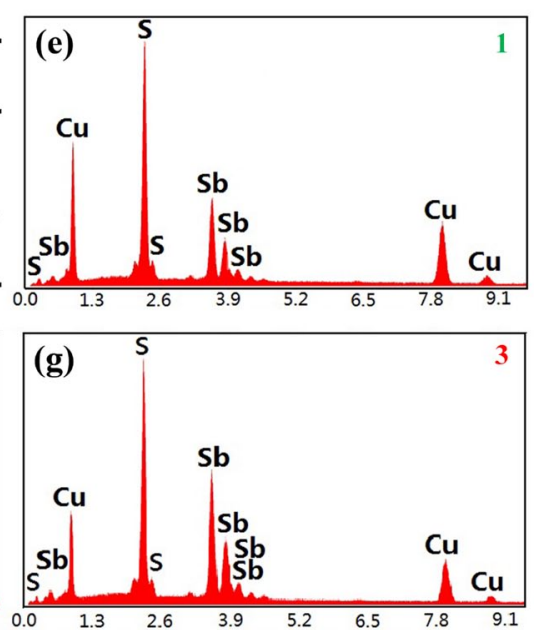

Fig. 4 BSE images and energy dispersive X-ray spectroscopy (EDX) data of the bulk samples with the mole ratio of $(1-x) \mathrm{CuSbS}_{2}-x \mathrm{Cu}_{1.8} \mathrm{~S}(x=0.2,0.3)$. (a) $x=0.2$, (b, c) $x=0.3$, (d) atomic ratio of $\mathrm{Cu} / \mathrm{Sb} / \mathrm{S}$, and (e) $-(\mathrm{g})$ EDX spectra. 
images of $x=0.3$ (Fig. 4(c)), in which the atomic ratio of $\mathrm{Cu}, \mathrm{Sb}$, and $\mathrm{S}$ at different positions (Fig. 4(d)), and EDX spectra are selected from the second phases (positions 1 and 2) and the matrix (position 3) (Figs. 4(e)$4(\mathrm{~g})$ ). Three elements $\mathrm{Cu}, \mathrm{Sb}$, and $\mathrm{S}$ were found both in the matrix (position 3) and the second phases (positions 1 and 2), but the composition of the matrix and the second phases is different. The atomic ratio of $\mathrm{Cu}, \mathrm{Sb}$, and $\mathrm{S}$ in the matrix (position 3) in Fig. 4(d) is almost similar around 1.25:1:2.16, which is consistent with the composition of $\mathrm{CuSbS}_{2}$. The atomic ratio of $\mathrm{Cu}, \mathrm{Sb}$, and $\mathrm{S}$ for the second phases shows different values at different positions, which is about 3.43:1:4.68 (position 1) and 2.78:1:3.41 (position 2) corresponding to the composition of $\mathrm{Cu}_{3} \mathrm{SbS}_{4}$ and $\mathrm{Cu}_{12} \mathrm{Sb}_{4} \mathrm{~S}_{13}$, respectively.

Figure 5 shows the FESEM images of the fractured surfaces for the bulk samples with the mole ratio of $(1-x) \mathrm{CuSbS}_{2}-x \mathrm{Cu}_{1.8} \mathrm{~S}(x=0,0.1,0.2,0.3)$. The grain sizes are refined from $0.72 \mu \mathrm{m}$ for $x=0$ to $0.62 \mu \mathrm{m}$ for $0.1 \leqslant x \leqslant 0.2$, and further reduce to $0.47 \mu \mathrm{m}$ as $x$ increasing to 0.3 . The refined grains are owing to the pinning effect of $\mathrm{Cu}_{3} \mathrm{SbS}_{4}$ and $\mathrm{Cu}_{12} \mathrm{Sb}_{4} \mathrm{~S}_{13}$ which would inhibit the grain growth. All samples have a porous microstructure, whose relative density increases from $82.52 \%$ to $88.59 \%$ when $x$ ranges from 0 to 0.2 , and then decreases to $84.47 \%$ at $x=0.3$ as shown in Table 1 and Fig. 5(e). The similar grain sizes and increased density at $0.1 \leqslant x \leqslant 0.2$ may lead to a higher $\kappa$, while the obvious refined grains and decreased density would probably reduce the $\kappa$ which would be clearly addressed later.

\section{3 TE transport properties}

Figure 6 shows the temperature dependence of electrical transport properties for the bulk samples with the mole ratio of $(1-x) \mathrm{CuSbS}_{2}-x \mathrm{Cu}_{1.8} \mathrm{~S}(x=0,0.1,0.2$, $0.3)$. The highest $\sigma$ in the whole measured temperature ranges from 373 to $723 \mathrm{~K}$ is almost the same which is located at ca. 0.54 and $0.68 \mathrm{~S} \cdot \mathrm{cm}^{-1}$ at $x=0$ and 0.1 . The low $\sigma$ of $x=0$ may be attributed to a low hole carrier concentration $(n)$. What's more, the lack of $\mathrm{S}$ in Eq. (1) would also reduce $n$ and leads to a lower $\sigma$. When $x$ increases to 0.1 , the formation of $\mathrm{Cu}$-rich $\mathrm{CuSbS}_{2}$ phase would introduce the substitution of $\mathrm{Sb}^{3+}$ by $\mathrm{Cu}^{+}$and/or $\mathrm{Cu}^{2+}$ as shown in Eqs. (3) and (4) which would increase $n$. Although the interstice solution of $\mathrm{Cu}^{+}$and/or $\mathrm{Cu}^{2+}$ in Eqs. (5) and (6) would introduce $\mathrm{e}^{\prime}$ and reduce $n$ as $x$ further increasing to 0.2 and 0.3 , the $\sigma$ value at $373 \mathrm{~K}$ is significantly enhanced to 6.78 $\mathrm{S} \cdot \mathrm{cm}^{-1}(x=0.2)$ and $76.41 \mathrm{~S} \cdot \mathrm{cm}^{-1}(x=0.3)$. The significantly enhanced $\sigma$ in Fig. 6 is not only because of the increased relative density from $82.52 \%$ to $88.59 \%$ as $x$ ranging from 0 to 0.2 . What's more, the $\sigma$ continues to increase while the relative density decreases to $84.47 \%$ at $x=0.3$, indicating the TE performance of the second phases may play a dominant role at $x \geqslant 0.2$. According to the electrical conductivity law of mixtures [22], the logarithm of the total $\sigma$ can be expressed as follows:

$$
\ln \sigma_{\mathrm{T}}=V_{\mathrm{M}} \ln \sigma_{\mathrm{M}}+V_{\mathrm{S}} \ln \sigma_{\mathrm{S}}
$$

where $\sigma_{\mathrm{T}}, V_{\mathrm{M}}, \sigma_{\mathrm{M}}, V_{\mathrm{S}}$, and $\sigma_{\mathrm{S}}$ are the total $\sigma$, volume fraction and $\sigma$ of the matrix and the second phase,
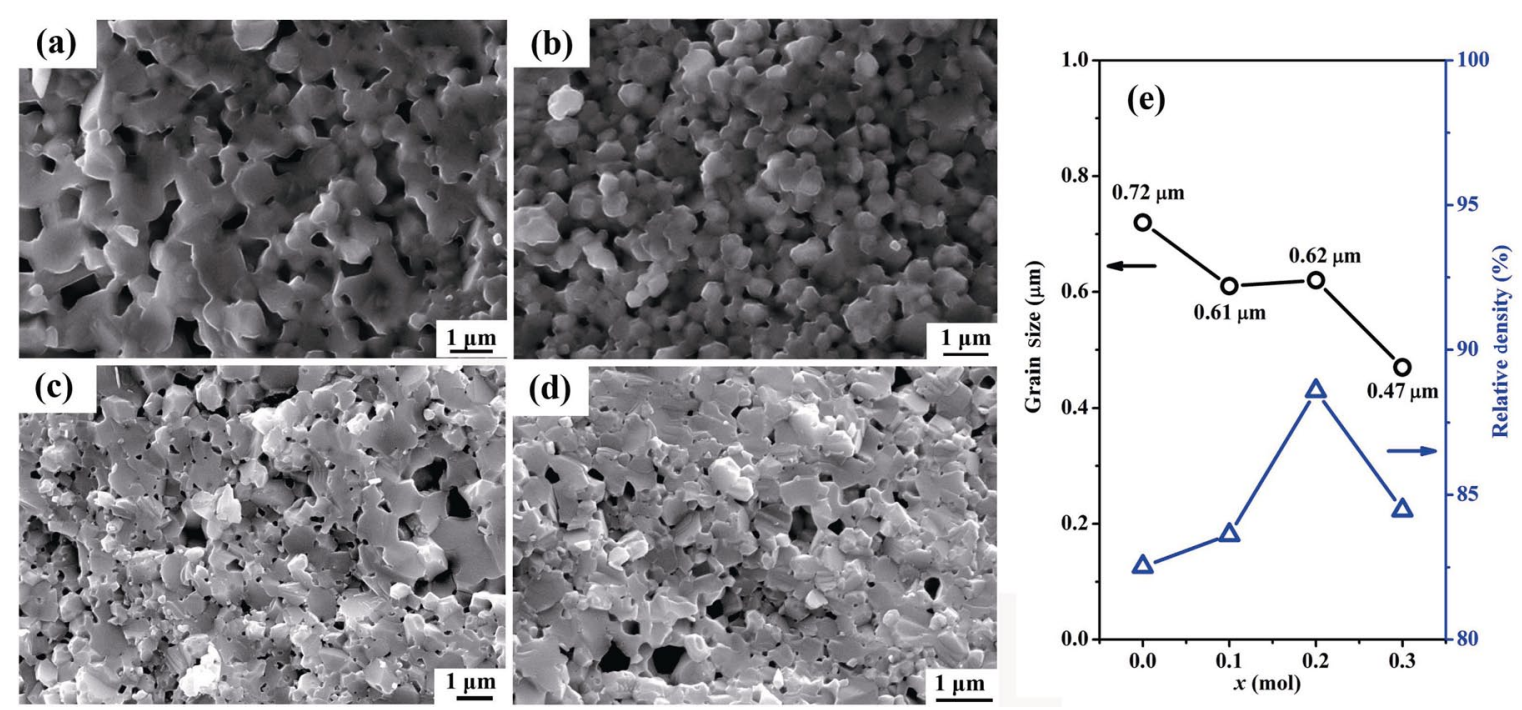

Fig. 5 FESEM images of the fractured surfaces and relative densities for the bulk samples with the mole ratio of $(1-x) \mathrm{CuSbS}_{2}-x \mathrm{Cu}_{1.8} \mathrm{~S}(x=0,0.1,0.2,0.3)$ : (a) $x=0$, (b) $x=0.1$, (c) $x=0.2$, (d) $x=0.3$, and (e) grain size and relative density. 

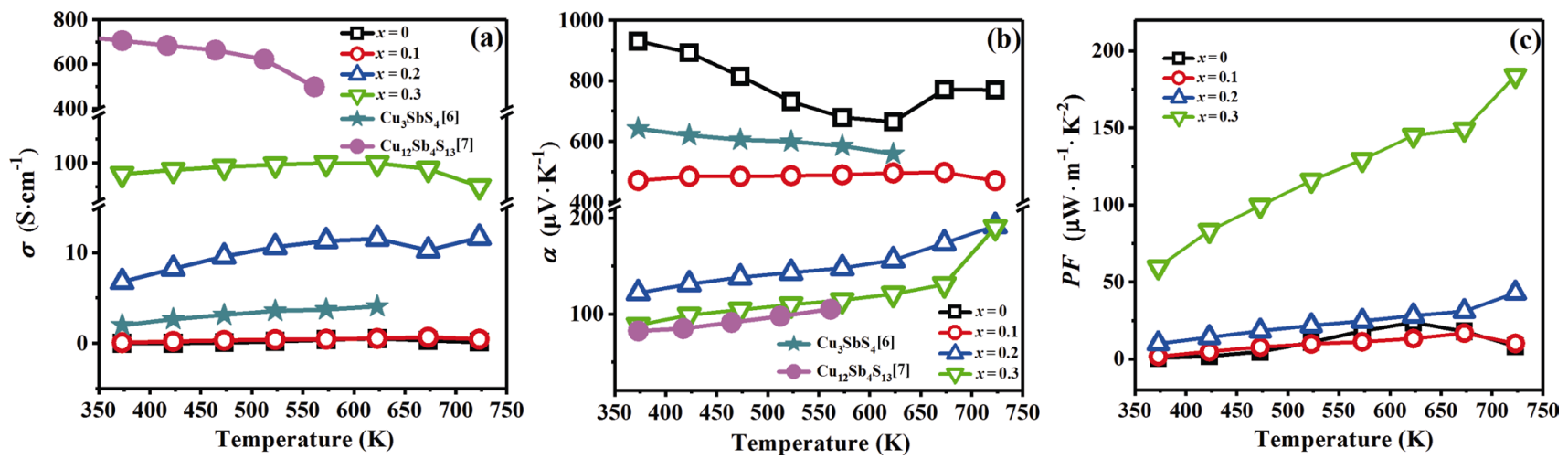

Fig. 6 Temperature dependence of electrical transport properties for the bulk samples with the mole ratio of $(1-x) \mathrm{CuSbS}_{2}-x \mathrm{Cu}_{1.8} \mathrm{~S}(x=0,0.1,0.2,0.3)$. (a) Electrical conductivity $(\sigma)$, (b) Seebeck coefficient $(\alpha)$, and (c) power factor (PF).

respectively. The increased $V_{\mathrm{S}}$ of the high-conductive second phases and the decreased $V_{\mathrm{M}}$ of low-conductive $\mathrm{CuSbS}_{2}$ in Table 1 would lead to the enhancement of $\sigma_{\mathrm{T}}$ according to Eq. (9). Chen et al. [6] reported that the $\sigma$ of $\mathrm{Cu}_{3} \mathrm{SbS}_{4}$ was ca. $2.01 \mathrm{~S} \cdot \mathrm{cm}^{-1}$ at $373 \mathrm{~K}$, while $\mathrm{Cu}_{12} \mathrm{Sb}_{4} \mathrm{~S}_{13}$ which was synthesized by the solid-state reaction at $723 \mathrm{~K}$ for 3 weeks and sintered at $723 \mathrm{~K}$ under $10 \mathrm{MPa}$ pressure showed a high $\sigma$ of 706.16 $\mathrm{S} \cdot \mathrm{cm}^{-1}$ [7], along with a metal like P-type conductivity calculated by DFT [8]. It is reasonable that the slightly increased $\sigma$ at $x=0.1$ is attributed to the formation of a little of the second phases whose $\sigma$ is higher than $\mathrm{CuSbS}_{2}\left(\sim 0.01 \mathrm{~S} \cdot \mathrm{cm}^{-1}\right)$. The remarkably enhanced $\sigma$ at $0.2 \leqslant x \leqslant 0.3$ should be attributed to the additional appearance of high-conductive $\mathrm{Cu}_{12} \mathrm{Sb}_{4} \mathrm{~S}_{13}$ (shown in Figs. 2(d), 3(d), 3(f), and Eq. (2)). Table 2 shows the electrical and thermal transport properties at $373 \mathrm{~K}$ for all the bulk samples with the mole ratio of $(1-x) \mathrm{CuSbS}_{2}-x \mathrm{Cu}_{1.8} \mathrm{~S} \quad(x=0,0.1,0.2,0.3)$, the $\mathrm{Cu}_{3} \mathrm{SbS}_{4}$ and $\mathrm{Cu}_{12} \mathrm{Sb}_{4} \mathrm{~S}_{13}$ second phases as well as the raw $\mathrm{Cu}_{1.8} \mathrm{~S}$. The high $\sigma$ of $\mathrm{Cu}_{1.8} \mathrm{~S}$ up to $3353 \mathrm{~S} \cdot \mathrm{cm}^{-1}$ still indicates a great potential to enhance the electrical transport properties of $\mathrm{CuSbS}_{2}$, although the raw $\mathrm{Cu}_{1.8} \mathrm{~S}$ phase is absent in the final bulk samples by applying
MA combined with SPS. How to composite $\mathrm{Cu}_{1.8} \mathrm{~S}$ with $\mathrm{CuSbS}_{2}$ is still a big challenge in the future.

The positive $\alpha$ value for all samples in Fig. 6(b) confirms the P-type semi conductive behavior, whose values all decrease with raising $x$ from 0 to 0.3 in the whole measured temperature range from 373 to $723 \mathrm{~K}$, which is contrary to the variation of $\sigma$. The second phases show a higher $\sigma$ associated with a lower $\alpha$ in Table 2 . The gradually reduced $\alpha$ value is mainly attributed to the low $\alpha$ of $\mathrm{Cu}_{12} \mathrm{Sb}_{4} \mathrm{~S}_{13}\left(\sim 82.26 \mu \mathrm{V} \cdot \mathrm{K}^{-1}\right)$ and $\mathrm{Cu}_{3} \mathrm{SbS}_{4} \quad\left(\sim 641.88 \mu \mathrm{V} \cdot \mathrm{K}^{-1}\right)$ second phases compared with $\mathrm{CuSbS}_{2}\left(\sim 930.5 \mu \mathrm{V} \cdot \mathrm{K}^{-1}\right)$. Due to the high $\sigma$ and the appropriate $\alpha$ value, the power factor $\left(P F=\alpha^{2} \sigma\right)$ in Fig. $6(\mathrm{c})$ peaks at $183 \mu \mathrm{W} \cdot \mathrm{m}^{-1} \cdot \mathrm{K}^{-2}$ and at $723 \mathrm{~K}$ when $x=0.3$.

Figure 7(a) shows the temperature dependence of $\kappa$ for the bulk samples with the mole ratio of $(1-x) \mathrm{CuSbS}_{2}-x \mathrm{Cu}_{1.8} \mathrm{~S}(x=0,0.1,0.2,0.3)$. The $\kappa$ of $\mathrm{CuSbS}_{2}$ is $1.27 \mathrm{~W} \cdot \mathrm{m}^{-1} \cdot \mathrm{K}^{-1}$ at $373 \mathrm{~K}$ which is little higher than $1.06 \mathrm{~W} \cdot \mathrm{m}^{-1} \cdot \mathrm{K}^{-1}$ reported by Du et al. [5]. The increased $\kappa$ as $x$ ranging from 0 to 0.2 is attributed to the increased density and the high $\kappa$ of $\mathrm{Cu}_{3} \mathrm{SbS}_{4}$ $\left(\sim 1.80 \mathrm{~W} \cdot \mathrm{m}^{-1} \cdot \mathrm{K}^{-1}\right)$ shown in Tables 1 and $2[6]$. However, the $\kappa$ still increases above $473 \mathrm{~K}$ when the

Table 2 TE transport properties of bulk samples and second phases at $373 \mathrm{~K}$

\begin{tabular}{|c|c|c|c|c|c|c|}
\hline Sample & Phase & Crystal structure & $\sigma\left(\mathrm{S} \cdot \mathrm{cm}^{-1}\right)$ & $\alpha\left(\mu \mathrm{V} \cdot \mathrm{K}^{-1}\right)$ & $\kappa\left(\mathrm{W} \cdot \mathrm{m}^{-1} \cdot \mathrm{K}^{-1}\right)$ & $Z T$ \\
\hline$x=0$ & $\mathrm{CuSbS}_{2}$ & Orthorhombic & 0.01 & 930.50 & 1.27 & 0.0001 \\
\hline$x=0.1$ & $\mathrm{CuSbS}_{2}+\mathrm{Cu}_{3} \mathrm{SbS}_{4}+\mathrm{Cu}_{12} \mathrm{Sb}_{4} \mathrm{~S}_{13}$ & - & 0.08 & 470.57 & 0.90 & 0.0007 \\
\hline$x=0.2$ & $\mathrm{CuSbS}_{2}+\mathrm{Cu}_{3} \mathrm{SbS}_{4}+\mathrm{Cu}_{12} \mathrm{Sb}_{4} \mathrm{~S}_{13}$ & - & 6.78 & 122.00 & 1.31 & 0.0028 \\
\hline$x=0.3$ & $\mathrm{CuSbS}_{2}+\mathrm{Cu}_{3} \mathrm{SbS}_{4}+\mathrm{Cu}_{12} \mathrm{Sb}_{4} \mathrm{~S}_{13}$ & - & 76.41 & 88.36 & 1.27 & 0.0175 \\
\hline- & $\mathrm{Cu}_{3} \mathrm{SbS}_{4}[6]$ & Tetragonal & 2.01 & 641.88 & 1.80 & 0.0171 \\
\hline- & $\mathrm{Cu}_{12} \mathrm{Sb}_{4} \mathrm{~S}_{13}[7]$ & Cubic & 706.16 & 82.26 & 1.09 & 0.1635 \\
\hline- & $\mathrm{Cu}_{1.8} \mathrm{~S}[16]$ & Rhombohedral & 3353.05 & 22.64 & 2.26 & 0.0284 \\
\hline
\end{tabular}


density decreases to $4.21 \mathrm{~g} / \mathrm{cm}^{3}$ at $x=0.3$, which may be due to the formation of a large amount of $\mathrm{Cu}_{12} \mathrm{Sb}_{4} \mathrm{~S}_{13}$ with a high $\kappa$ above $473 \mathrm{~K}$. The lowest $\kappa$ $0.47 \mathrm{~W} \cdot \mathrm{m}^{-1} \cdot \mathrm{K}^{-1}$ for $\mathrm{CuSbS}_{2}$ is achieved at $723 \mathrm{~K}$. The $\kappa_{\mathrm{e}}$ could be estimated by the Wiedemann-Franz relation: $\kappa_{\mathrm{e}}=L \sigma T$, where $L$ is the Lorenz number, $T$ is the absolute temperature. For nondegenerate semiconductor, $L$ was calculated to be $1.485 \times 10^{-8} \mathrm{~W} \cdot \Omega \cdot \mathrm{K}^{-2}$ based on the assumption of $r=-1 / 2$ for acoustic phonon scattering according to Eq. (10) where $k_{\mathrm{B}}$ is the Boltzmann constant, $e$ is the electron charge, and $r$ is the scattering factor $[23,24]$.

$$
L=\left(\frac{k_{\mathrm{B}}}{e}\right)^{2}\left(r+\frac{5}{2}\right)
$$

Figures 7(b) and 7(c) show the temperature dependence of $\kappa_{\mathrm{e}}$ and $\kappa_{\mathrm{L}}$. The $\kappa_{\mathrm{L}}$ plays a dominant role in the thermal transport performance owning to the low $\sigma$ resulting in an almost negligible $\kappa_{\mathrm{e}}$. The increased $\kappa_{\mathrm{L}}$ as $x$ ranging from 0 to 0.2 is attributed to the high $\kappa_{\mathrm{L}}$ of $\mathrm{Cu}_{3} \mathrm{SbS}_{4}$ which plays a dominated role compared to the contribution of increased alloy scattering and $\mathrm{Cu}_{12} \mathrm{Sb}_{4} \mathrm{~S}_{13}$. When $x=0.3$, the amount of $\mathrm{Cu}_{12} \mathrm{Sb}_{4} \mathrm{~S}_{13}$ is further increased as shown in Table 1 and the $\kappa_{\mathrm{L}}$ shows a slight reduction in Fig. 7(c). The decreased $\kappa_{\mathrm{L}}$ of $x=$
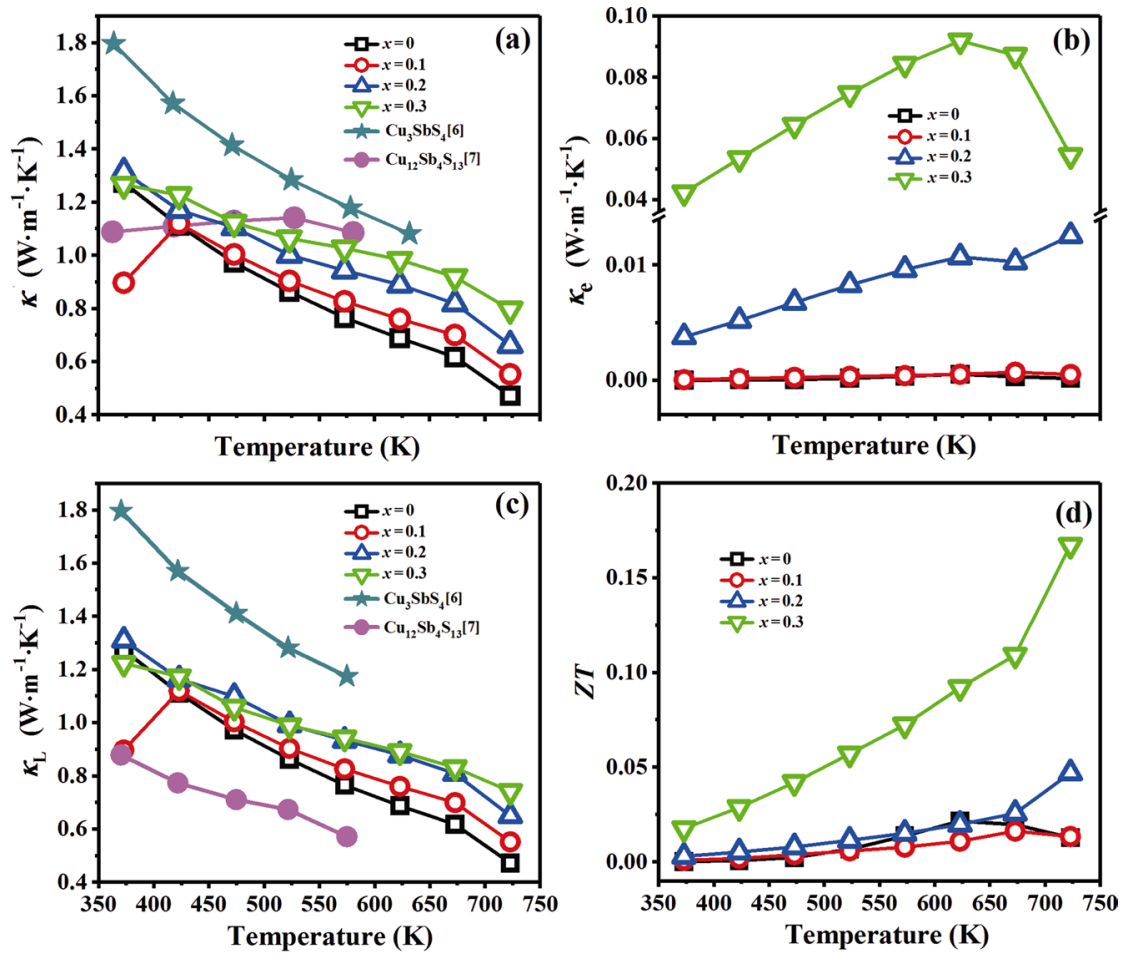

Fig. 7 Temperature dependence of thermal transport properties and $Z T$ value for the bulk samples with the mole ratio of $(1-x) \mathrm{CuSbS}_{2}-x \mathrm{Cu}_{1.8} \mathrm{~S}(x=0,0.1,0.2,0.3)$ : (a) thermal conductivity $(\kappa)$, (b) electronic thermal conductivity $\left(\kappa_{\mathrm{e}}\right)$, (c) lattice thermal conductivity $\left(\kappa_{\mathrm{L}}\right)$, and $(\mathrm{d}) Z T$ value.

0.3 may be owning to the lower $\kappa_{\mathrm{L}}$ of $\mathrm{Cu}_{12} \mathrm{Sb}_{4} \mathrm{~S}_{13}$ rather than the further increased alloy scattering. Moreover, the refined grain shown in Figs. 5(d) and 5(e) could also enhance the grain boundary scattering and lower the $\kappa_{\mathrm{L}}$.

Figure 7(d) shows temperature dependence of $Z T$ for the bulk samples with the mole ratio of $(1-x) \mathrm{CuSbS}_{2}-x \mathrm{Cu}_{1.8} \mathrm{~S} \quad(x=0, \quad 0.1, \quad 0.2, \quad 0.3)$. Significantly enhanced $P F$ and slightly deteriorated $\kappa$ for $0.2 \leqslant x \leqslant 0.3$ result in a higher $Z T$ compared with $\mathrm{CuSbS}_{2}$. The highest $Z T$ value of 0.17 at $723 \mathrm{~K}$ was obtained when $x=0.3$.

\section{Conclusions}

P-type $\mathrm{CuSbS}_{2}$ based TE composites with a mole ratio of $(1-x) \mathrm{CuSbS}_{2}-x \mathrm{Cu}_{1.8} \mathrm{~S}(x=0,0.1,0.2,0.3)$ were fabricated by MA combined with SPS. The correlation between the phase structure, microstructure, and TE transport properties of the bulk samples is systematically investigated. A single phase of $\mathrm{CuSbS}_{2}$ is synthesized at $x=0$ and the samples consist of $\mathrm{CuSbS}_{2}, \mathrm{Cu}_{3} \mathrm{SbS}_{4}$, and $\mathrm{Cu}_{12} \mathrm{Sb}_{4} \mathrm{~S}_{13}$ at $0.1 \leqslant x \leqslant 0.3$. The $\sigma$ significantly increases from 0.14 to $50.66 \mathrm{~S} \cdot \mathrm{cm}^{-1}$ at $723 \mathrm{~K}$ when $0 \leqslant$ $x \leqslant 0.03$, while the $\alpha$ holds an appropriate value of 
$190.51 \mu \mathrm{V} \cdot \mathrm{K}^{-1}$. The highest $Z T$ value of 0.17 is obtained at $723 \mathrm{~K}$ for $x=0.3$ bulk sample owing to the combination of a high $P F 183 \mu \mathrm{W} \cdot \mathrm{m}^{-1} \cdot \mathrm{K}^{-2}$ and a low $\kappa$ $0.8 \mathrm{~W} \cdot \mathrm{m}^{-1} \cdot \mathrm{K}^{-1}$.

\section{Acknowledgements}

This work was supported by National Key R\&D Program of China (Grant No. 2018YFB0703600) and the National Natural Science Foundation of China (Grant No. 11474176).

\section{References}

[1] Huang SY, Xu XF. A regenerative concept for thermoelectric power generation. Appl Energy 2017, 185: $119-125$.

[2] Ge ZH, Zhao LD, Wu D, et al. Low-cost, abundant binary sulfides as promising thermoelectric materials. Mater Today 2016, 19: 227-239.

[3] Gassoumi A, H.-E MMS, Alfaify S, et al. The investigation of crystal structure, elastic and optoelectronic properties of $\mathrm{CuSbS}_{2}$ and $\mathrm{CuBiS}_{2}$ compounds for photovoltaic applications. J Alloys Compd 2017, 725: 181-189.

[4] Chen K. Synthesis and thermoelectric properties of $\mathrm{Cu}-\mathrm{Sb}-\mathrm{S}$ compounds. Ph.D. Thesis. London (UK): Queen Mary, University of London, 2016.

[5] Du BL, Zhang RZ, Chen K, et al. The impact of lone-pair electrons on the lattice thermal conductivity of the thermoelectric compound $\mathrm{CuSbS}_{2}$. J Mater Chem A 2017, 5: 3249-3259.

[6] Chen K, Du BL, Bonini N, et al. Theory-guided synthesis of an eco-friendly and low-cost copper based sulfide thermoelectric material. $J$ Phys Chem C 2016, 120: 27135-27140.

[7] Heo J, Laurita G, Muir S, et al. Enhanced thermoelectric performance of synthetic tetrahedrites. Chem Mater 2014, 26: 2047-2051.

[8] Lu X, Morelli DT, Xia Y, et al. High performance thermoelectricity in earth-abundant compounds based on natural mineral tetrahedrites. Adv Energy Mater 2013, 3: 342-348.

[9] Lu X, Morelli D. The effect of Te substitution for Sb on thermoelectric properties of tetrahedrite. J Electron Mater 2014, 43: 1983-1987.

[10] Kumar Gudelli V, Kanchana V, Vaitheeswaran G, et al. Thermoelectric properties of chalcopyrite type $\mathrm{CuGaTe}_{2}$ and chalcostibite $\mathrm{CuSbS}_{2}$. J Appl Phys 2013, 114: 223707.

[11] Rodríguez-Lazcano Y, Nair MTS, Nair PK. $\mathrm{CuSbS}_{2}$ thin film formed through annealing chemically deposited $\mathrm{Sb}_{2} \mathrm{~S}_{3}$-CuS thin films. J Cryst Growth 2001, 223: 399-406.

[12] Rodríguez-Lazcano Y, Nair MTS, Nair PK. Photovoltaic $\mathrm{p}-\mathrm{i}-\mathrm{N}$ structure of $\mathrm{Sb}_{2} \mathrm{~S}_{3}$ and $\mathrm{CuSbS}_{2}$ absorber films obtained via chemical bath deposition. J Electrochem Soc
2005, 152: G635.

[13] Rabhi A, Kanzari M. Structural, optical and electrical properties of $\mathrm{CuSbS}_{2}$ these amorphous films: effect of the thickness variation. Chalcogenide Lett 2011, 8: 383-390.

[14] Liang DD, Ge ZH, Li HZ, et al. Enhanced thermoelectric property in superionic conductor Bi-doped $\mathrm{Cu}_{1.8} \mathrm{~S}$. J Alloys Compd 2017, 708: 169-174.

[15] Ge ZH, Zhang BP, Chen YX, et al. Synthesis and transport property of $\mathrm{Cu}_{1.8} \mathrm{~S}$ as a promising thermoelectric compound. Chem Commun 2011, 47: 12697-12699.

[16] Yao Y, Zhang BP, Pei J, et al. Improved thermoelectric transport properties of $\mathrm{Cu}_{1.8} \mathrm{~S}$ with $\mathrm{NH}_{4} \mathrm{Cl}$-derived mesoscale-pores and point-defects. Ceram Int 2016, 42: 17518-17523.

[17] Li JF, Pan Y, Wu CF, et al. Processing of advanced thermoelectric materials. Sci China Technol Sci 2017, 60: 1347-1364.

[18] Saal JE, Kirklin S, Aykol M, et al. Materials design and discovery with high-throughput density functional theory: The open quantum materials database (OQMD). JOM 2013, 65: 1501-1509.

[19] Kirklin S, Saal JE, Meredig B, et al. The open quantum materials database (OQMD): Assessing the accuracy of DFT formation energies. npj Comput Mater 2015, 1: 15010 .

[20] Zou L, Zhang BP, Ge ZH, et al. Size effect of $\mathrm{SiO}_{2}$ on enhancing thermoelectric properties of $\mathrm{Cu}_{1.8} \mathrm{~S}$. Phys Status Solidi A 2013, 210: 2550-2555.

[21] Zheng LJ, Zhang BP, Li HZ, et al. $\mathrm{Cu}_{x} \mathrm{~S}$ superionic compounds: Electronic structure and thermoelectric performance enhancement. J Alloys Compd 2017, 722: $17-24$.

[22] Ge ZH, Zhang BP, Yu YQ, et al. Fabrication and properties of $\mathrm{Bi}_{2-x} \mathrm{Ag}_{3 x} \mathrm{~S}_{3}$ thermoelectric polycrystals. $J$ Alloys Compd 2012, 514: 205-209.

[23] Goldsmid HJ. Introduction to Thermoelectricity. Berlin (Germany): Springer-Verlag Berlin Heidelberg, 2010.

[24] Pei J, Zhang BP, Li JF, et al. Maximizing thermoelectric performance of $\mathrm{AgPb}_{m} \mathrm{SbTe}_{m+2}$ by optimizing spark plasma sintering temperature. J Alloys Compd 2017, 728: 694-700.

Open Access This article is licensed under a Creative Commons Attribution 4.0 International License, which permits use, sharing, adaptation, distribution and reproduction in any medium or format, as long as you give appropriate credit to the original author(s) and the source, provide a link to the Creative Commons licence, and indicate if changes were made.

The images or other third party material in this article are included in the article's Creative Commons licence, unless indicated otherwise in a credit line to the material. If material is not included in the article's Creative Commons licence and your intended use is not permitted by statutory regulation or exceeds the permitted use, you will need to obtain permission directly from the copyright holder.

To view a copy of this licence, visit http://creativecommons. org/licenses/by/4.0/. 